\title{
Tocilizumab in Severe COVID-19 Pneumonia and Concomitant Cytokine Release Syndrome
}

\author{
$\underline{T o m ~ D A ~ v a n ~ K r a a i j ~}^{1}$, Rémy LM Mostard ${ }^{1}$, Sofia Ramiro ${ }^{2,5}$, Cesar Magro Checa ${ }^{2}$, Christel MP van Dongen ${ }^{2}$, Eric HJ van Haren ${ }^{1}$, \\ Jacqueline Buijs ${ }^{3}$, Robert BM Landewé2,4 \\ ${ }^{1}$ Department of Pulmonology, Zuyderland Medical Center, Heerlen-Sittard, the Netherlands \\ ${ }^{2}$ Department of Rheumatology, Zuyderland Medical Center, Heerlen-Sittard, the Netherlands \\ ${ }^{3}$ Department of Internal Medicine, Zuyderland Medical Center, Heerlen-Sittard, the Netherlands \\ ${ }^{4}$ Department of Rheumatology, Amsterdam University Medical Center (ARC), Amsterdam, the Netherlands \\ ${ }^{5}$ Department of Rheumatology, Leiden University Medical Center, Leiden, the Netherlands
}

\section{Doi: 10.12890/2020_001675- European Journal of Case Reports in Internal Medicine - @ EFIM 2020}

Received: $19 / 04 / 2020$

Accepted: 20/04/2020

Published: $22 / 04 / 2020$

How to cite this article: van Kraaij TDA, Mostard RLM, Ramiro S, Magro Checa C, van Dongen CMP, van Haren EHJ, Buijs J, Landewé RBM. Tolicizumab in severe COVID-19 pneumonia and concomitant cytokine release syndrome. EJCRIM 2020;7: doi:10.12890/2020_001675.

Conflicts of Interests: The Authors declare that there are no competing interests.

Acknowledgements: The authors would like to acknowledge M Leers, PhD (Department of Clinical Chemistry, Zuyderland Medical Center, Heerlen-

Sittard, the Netherlands) for his valuable contributions to this manuscript.

This article is licensed under a Commons Attribution Non-Commercial 4.0 License

\section{ABSTRACT}

Younger patients with COVID-19 may experience an exaggerated immune response to SARS-CoV-2 infection and develop cytokine release syndrome (CRS), which may be life threatening. There is no proven antiviral therapy for COVID-19 so far, but profound immunosuppression has recently been suggested as a treatment for COVID-19-associated CRS. We present a case of life-threatening CRS caused by COVID-19 infection with a favourable response to immunosuppressive therapy with tocilizumab (TCZ). The rapid clinical and biochemical improvement following TCZ administration suggests that treatment with immunotherapy can be life-saving in selected patients with COVID-19-induced CRS.

\section{LEARNING POINTS}

- Cytokine release syndrome may cause sudden and potentially life-threatening clinical deterioration in COVID-19 pneumonia, particularly in younger patients.

- Immunosuppressive therapy may provide important additional therapeutic benefit in these patients.

- Tocilizumab, a specific IL-6 inhibitor, led to dramatic clinical improvement in a young patient with severe COVID-19-associated cytokine release syndrome.

\section{KEYWORDS}

COVID-19, cytokine release syndrome, tocilizumab

\section{BACKGROUND}

Patients admitted with COVID-19 pneumonia are often old with many comorbidities. However, younger patients seem to primarily experience an exaggerated response of their immune system to COVID-19 pulmonary infection, and develop features of cytokine release syndrome (CRS), which may be life threatening ${ }^{[1,2]}$. 
Thus far, there is no proven antiviral therapy for COVID-19, but profound immunosuppression has recently been suggested as a treatment for COVID-19-associated CRS ${ }^{[3]}$. We describe a case of life-threatening CRS caused by COVID-19 infection with a favourable response to immunosuppressive therapy with tocilizumab (TCZ).

\section{CASE DESCRIPTION}

A 26-year-old, previously healthy man was referred to our emergency department on 28 March with a 5-day history of fever, dyspnoea and cough. He walked into the emergency department independently, but within 1 hour needed an oxygen supply of $15 \mathrm{I} / \mathrm{min}$ on an OxyMask to maintain his oxygen saturation at $90 \%$. A pulmonary CT scan showed extensive areas of ground-glass opacities and subtle consolidations bilaterally, predominantly in the basal lung areas, with some extension to all pulmonary lobes (CO-RADS 5). A SARS-Corona E-swab PCR test returned a positive result within a few hours. Laboratory testing showed increased levels of C-reactive protein (CRP; $153 \mu \mathrm{g} / \mathrm{ml}$ ), ferritin $(703 \mathrm{ng} / \mathrm{ml})$ and D-dimer (3233 ng/ml). The diagnosis of COVID-19 pneumonia was made and treatment with chloroquine and prophylactic ceftriaxone and low-molecular weight heparin was initiated.

The patient was admitted to the intensive care unit for treatment with high-flow oxygen (Optiflow, 30 I; $65 \% \mathrm{FiO}_{2}$ ) resulting in a maximum $\mathrm{O}_{2}$ saturation of $93 \%$ and an arterial $\mathrm{pO}_{2}$ of $61.5 \mathrm{mmHg}$. On the second day of admission, the patient's respiratory condition further deteriorated and he had to be intubated for invasive ventilation in the prone position. As the extreme clinical deterioration in conjunction with laboratory findings (Fig. 1) raised a high suspicion of CRS, we decided to administer a single intravenous dose of TCZ at a dose of 8 $\mathrm{mg} / \mathrm{kg}$ body-weight. TCZ is an IL-6-receptor-blocking biological drug commonly used in the treatment of autoimmune disorders such as rheumatoid arthritis.

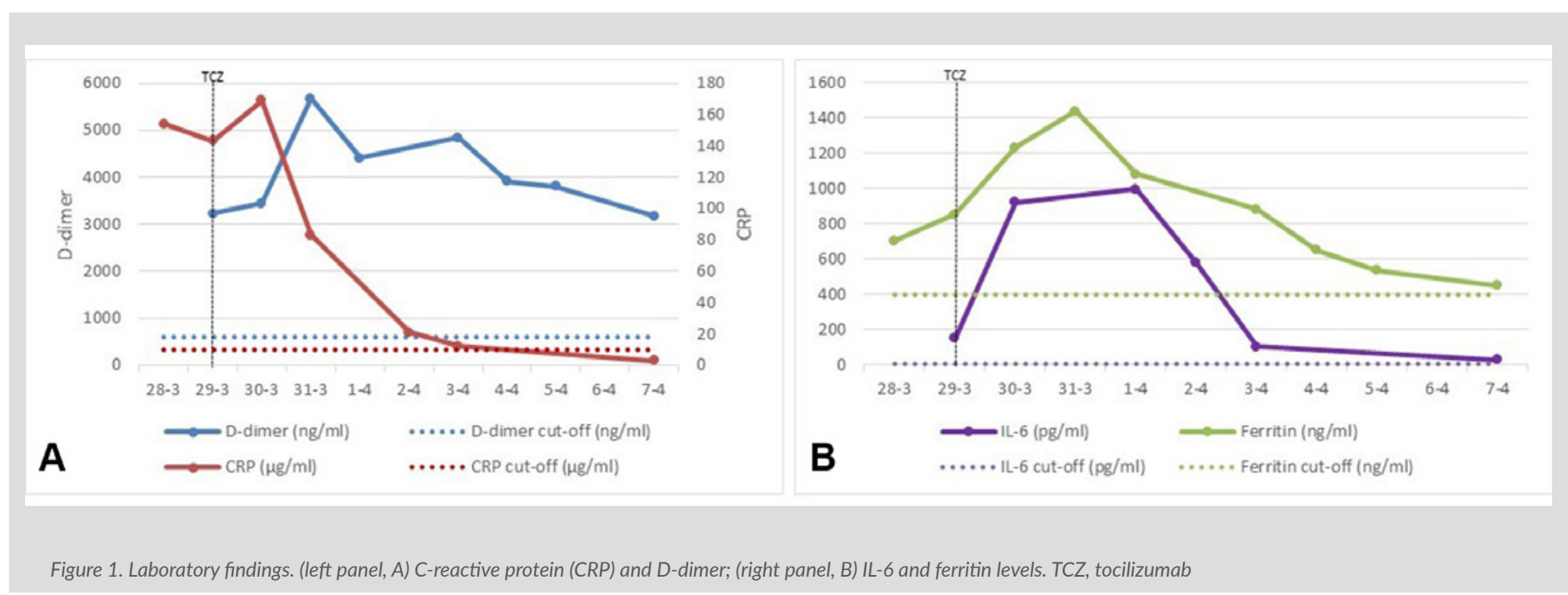

Initially, CRP, ferritin, D-dimer and IL-6 levels showed a further increase, suggestive of advancing CRS. However, from 31 March onwards ( 2 days after TCZ administration), ventilation conditions improved day-by-day. This was associated with a reversal of laboratory parameters toward normal levels of CRP, ferritin and IL-6 within 5 days of administration of TCZ. During this period, the patient was weaned from mechanical ventilation and successfully extubated. A chest x-ray performed on 5 April, 7 days after treatment with TCZ, showed complete resolution of abnormalities (Fig. 2). On 7 April, 9 days after treatment with TCZ, the patient was discharged from hospital without any need for supplemental oxygen.

\section{DISCUSSION}

IL-6 plays a key role in the pathogenesis of CRS, although its contribution has not yet been fully elucidated. TCZ, a biological drug that binds to the IL-6 receptor and prevents IL-6 from signalling, is used successfully in the treatment of autoimmune diseases. It has also been approved for the treatment of severe or life-threatening CRS associated with chimeric antigen receptor (CAR) T-cell immunotherapy in patients with malignancy ${ }^{[4,5]}$.

Our case strongly suggests that administration of a single dose of TCZ in advancing SARS-CoV-2-induced CRS (within a hypothesized window of opportunity) contributes to a surprising turnaround in an otherwise damaging clinical course. 


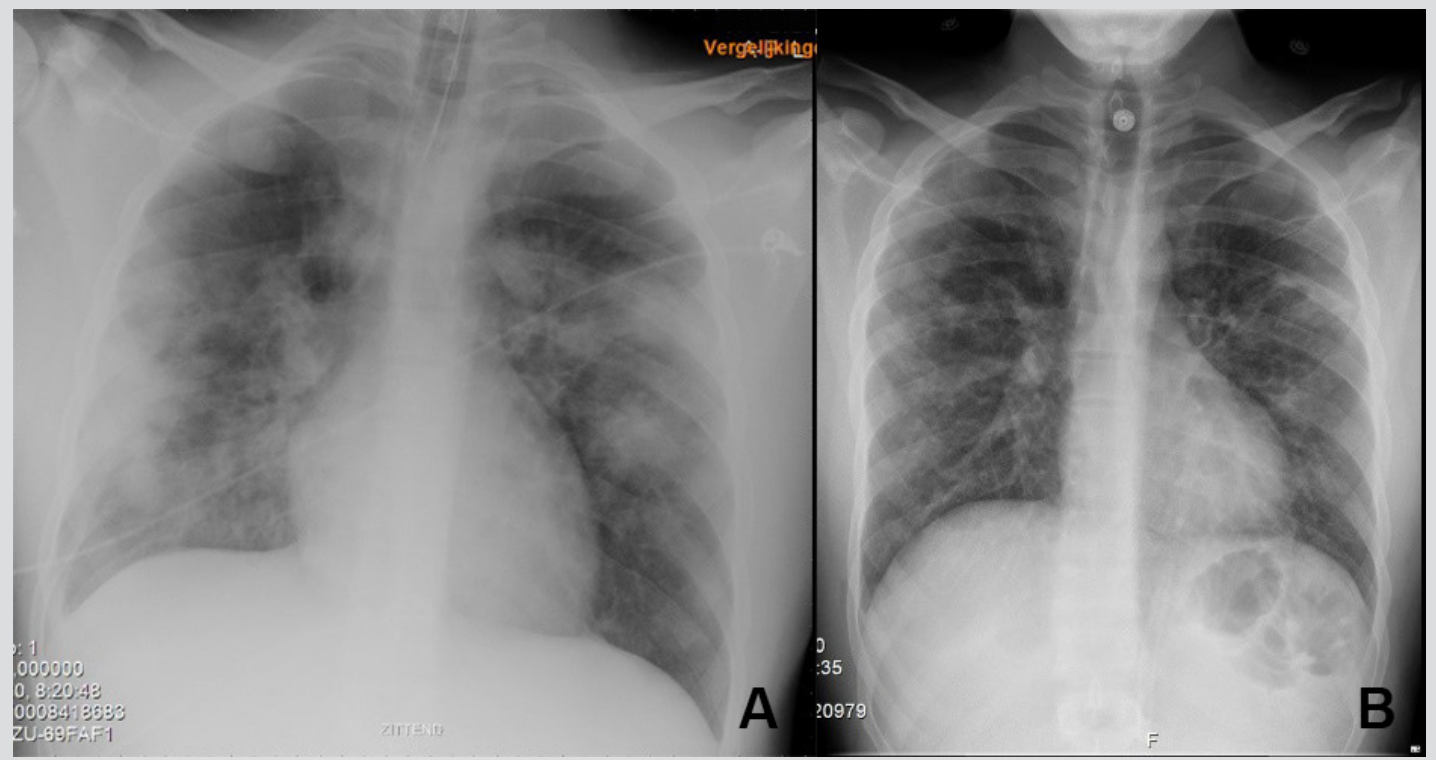

Figure 2. Chest $x$-ray on day 1 (left) of tocilizumab therapy compared with day 7 (right)

We cannot disregard the possibility that the patient's recovery was spontaneous and that the association with TCZ was coincidental. However, spontaneous recovery seems highly unlikely here, and is in distinct contrast to our recent clinical experience in similar patients. Patients with a similar catastrophic course often died or needed prolonged mechanical ventilation with uncertain outcome.

The rapid clinical and biochemical improvement following TCZ administration suggests that treatment with immunotherapy can be crucial and life-saving in selected patients with COVID-19-induced CRS. Ongoing clinical trials with TCZ will hopefully produce rapid results.

\section{REFERENCES}

1. Ruan Q, Yang K, Wang W, et al. Clinical predictors of mortality due to COVID-19 based on an analysis of data of 150 patients from Wuhan, China. Intensive Care Med 2020 Mar 3. doi: 10.1007/s00134-020-05991-x [Epub ahead of print].

2. Apoorva Mandavilli. The coronavirus patients betrayed by their own immune systems. The New York Times. 1st April 2020.

3. Mehta PM, McAuley DF, Brown M, et al. COVID-19: consider cytokine storm syndromes and immunosuppression. Lancet 2020;395(10229):1033-1034.

4. Maude SL, Laetsch TW, Buechner J, et al. Tisagenlecleucel in children and young adults with B-cell lymphoblastic leukemia. N Engl J Med 2018;378(5):439-448.

5. Le RQ, Li L, Yuan W, et al. FDA approval summary: tocilizumab for treatment of chimeric antigen receptor T cell-induced severe or life-threatening cytokine release syndrome. Oncologist 2018;23(8):943-947. 